OPEN ACCESS

Edited by:

Patrick Meyfroidt,

Catholic University of

Louvain, Belgium

Reviewed by:

Mangala De Zoysa,

University of Ruhuna, Sri Lanka

Mohammad Giasuddin,

Bangladesh Livestock Research

Institute, Bangladesh

${ }^{*}$ Correspondence:

Md. Ahasanul Hoque

md.hoque@my.jcu.edu.au

Specialty section:

This article was submitted to Land, Livelihoods and Food Security,

a section of the journal

Frontiers in Sustainable Food Systems

Received: 25 May 2021 Accepted: 02 August 2021 Published: 25 August 2021

Citation:

Sattar AA, Mahmud R, Mohsin MAS, Chisty NN, Uddin MH, Irin N,

Barnett T, Fournie G, Houghton E and Hoque MA (2021) COVID-19 Impact on Poultry Production and Distribution

Networks in Bangladesh.

Front. Sustain. Food Syst. 5:714649. doi: 10.3389/fsufs.2021.714649

\section{COVID-19 Impact on Poultry Production and Distribution Networks in Bangladesh}

\author{
Abdullah Al Sattar ${ }^{1}$, Rashed Mahmud ${ }^{1}$, Md. Abu Shoieb Mohsin ${ }^{1}$, Nurun Nahar Chisty ${ }^{1}$, \\ Md. Helal Uddin ${ }^{1}$, Nusrat Irin ${ }^{1}$, Tony Barnett ${ }^{2,3}$, Guillaume Fournie ${ }^{2}$, Eve Houghton ${ }^{2}$ and \\ Md. Ahasanul Hoque ${ }^{1 *}$
}

${ }^{1}$ Department of Medicine and Surgery, Faculty of Veterinary Medicine, Chattogram Veterinary and Animal Sciences University, Chattogram, Bangladesh, ${ }^{2}$ Veterinary Epidemiology, Economics and Public Health Group, Department of Pathobiology and Population Sciences, The Royal Veterinary College, University of London, London, United Kingdom, ${ }^{3}$ Firoz Lalji Institute for Africa, London School of Economics and Political Science, London, United Kingdom

The COVID-19 pandemic has severely affected numerous economic sectors across the world, including livestock production. This study investigates how the pandemic has impacted the poultry production and distribution network (PDN), analyses stakeholders' changing circumstances, and provides recommendations for rapid and long-term resilience. This is based on a literature review, social media monitoring, and key informant interviews $(n=36)$ from across the poultry sector in Bangladesh. These included key informants from breeder farms and hatcheries, pharmaceutical suppliers, feed companies, dealers, farmers, middlemen, and vendors. We show that the poultry sector was damaged by the COVID-19 pandemic, partly as a result of the lockdown and also by rumors that poultry and their products could transmit the disease. This research shows that hardly any stakeholder escaped hardship. Disrupted production and transportation, declining consumer demand and volatile markets brought huge financial difficulties, even leading to the permanent closure of many farms. We show that the extent of the damage experienced during the first months of COVID-19 was a consequence of how interconnected stakeholders and businesses are across the poultry sector. For example, a shift in consumer demand in live bird markets has ripple effects that impact the price of goods and puts pressure on traders, middlemen, farmers, and input suppliers alike. We show how this interconnectedness across all levels of the poultry industry in Bangladesh makes it fragile and that this fragility is not a consequence of COVID-19 but has been revealed by it. This warrants long-term consideration beyond the immediate concerns surrounding the COVID-19 pandemic.

Keywords: poultry sector, Bangladesh, CoVID-19, impact, rumor, transaction chains

\section{INTRODUCTION}

In addition to its impact on public health, COVID-19 has affected social and economic life in many ways. Areas impacted include the livestock production sector, at global, regional and national levels (Marchant-Forde and Boyle, 2020). Governmental actions, taken in attempts to control the pandemic, have included national lockdowns, travel restrictions, border closures and controls. These have resulted in some inevitable negative consequences. With regard to the livestock sector, 
these have included: (i) local and international movements of live animals and animal products; (ii) supplies of raw materials for feed and medicine; (iii) provision of other production inputs and equipment; (iv) access to labor and professional services (Food Agriculture Organization, 2020a).

In many countries, the closure of schools, restaurants, shops and markets, limitations on public gatherings and travel have reduced demand for animal products (InEuropa, 2020; Marchant-Forde and Boyle, 2020). Infections among workers and subsequent closure of slaughterhouses and food processing plant has reduced slaughtering and processing throughput (Good, 2020). These factors resulted in the overstocking or culling of animals and animal products (Huffstutter, 2020), with farmers depopulating their farms to reduce the costs of maintaining animal populations which they could neither feed nor trade (Barrett, 2020). Inevitably, this affected poultry production and trade (Mulder, 2020).

The impact on the Bangladesh poultry sector was devastating. Poultry production is the main livestock sector in Bangladesh, providing an important component of food security and contributing to the country's economic development more generally. Over 8.5 million people are employed in this sector, which is the second-most important source of employment after the garments industry (Hossain, 2020). Poultry accounts for $37 \%$ of the country's total meat production and $22-27 \%$ of the animal protein supply and forms a substantial fraction of the livestock sector's $1.4 \%$ contribution to the country's GDP (DLS: Department of Livestock Services, 2020). Of course, COVID-19 is by no means the first or only challenge this growing sector faces. The avian influenza outbreak of 2007 had catastrophic repercussions for the sector, shutting down more than half of the country's poultry farms and hatcheries, and the emergence of this disease continues to afflict poultry farmers (Gupta et al., 2021). Recurring outbreaks of other diseases in flocks have hampered overall production, leaving some farmers in precarious financial positions (Hamid et al., 2017). There are also structural challenges shaping the sector. Risks associated with the market, such as value chain fragmentation, high intermediation costs, and no or lack of traceability, all impede the distribution of poultry and poultry products (MoFood-Ministry of Food, 2020). The unregulated and fluctuating cost of certain critical farm inputs, including day-old chick (DOC) and feed, and uncertain market price of finished live poultry have also become a major worry for stakeholders. The strategies of feed manufacturing, promotion, and distribution differ amongst companies and hence they set prices unilaterally and are not subject to government regulation often (Hamid et al., 2017). Hatcheries raise the price of DOC for certain events and festivals, putting farmers at a disadvantage (Høg et al., 2019). Fluctuating prices are also a concern. Changes in supply and demand cause chicken and egg prices to change regularly, sometimes beyond the reach of many consumers, and sometimes so severely that farmers suffer financially. Moreover, the insufficient coordination between the country's public-private and research institutions and inadequate government oversight of the poultry sector is hampering the development of this sector (Hamid et al., 2017). Despite these challenges, COVID19 still presented a new and extreme challenge to the sector both introducing new problems and exacerbating some of these existing ones.

The first case of COVID-19 was reported in Bangladesh on 8 March 2020 (World Health Organization, 2020a). The government took measures to prevent the spread of the virus, including the implementation of a nationwide lockdown (referred to as "General Holiday") between 26 March and 30 May. During this period, the government ordered closure of all businesses and institutions other than hospitals, kitchen markets (kachar bazar $)^{1}$, pharmacies, and other emergency and health-related services (World Health Organization, 2020b). This study assesses the impacts of the first four months of the COVID-19 pandemic, and in particular the national lockdown, on the production, trade and marketing of chickens and eggs in Bangladesh.

This research focuses on four of the most important components of the chicken sector: (i) improved crossbred chickens called Sonali murgi; (ii) exotic broiler chickens; (iii) eggs from exotic layer birds; (iv) Deshi murgi ("backyard"/local/indigenous chickens). Here we first compare variations in the prices of different chicken commodities across the study period. We then explore the way in which the pandemic has affected the activities of different poultry production stakeholders.

\section{MATERIALS AND METHODS}

\section{Literature Review}

At an early stage of the COVID-19 epidemic in Bangladesh, we conducted a review of news articles published in mainstream print and electronic media. We compiled an analytical account of the diverse impacts of COVID-19 on the poultry sector in the country. The following resources were screened daily from 26 March to 31 May 2020: news channel (Somoy News), 12 Bangladeshi daily national newspapers (Prothom Alo, Financial express, Kalerkantha, Jugantor, Samakal, Ittefaq, Nayadiganta, Inqilab, Daily Star, The Independent, Bangladesh Pratidin, and The Azadi) and nine online news websites (Agrinews24, Adhunik Krishi Khamar, Poultry Doctors BD, Jagonews24, Banglanews24, BDnews24, UNB, Banglatribune and Bangla.24 Live Newspaper).

\section{Interviews}

Based on a list of poultry stakeholders compiled through the previous field studies (Høg et al., 2019; Gupta et al., 2021; Moyen et al., 2021) and a policy consultation (Chattopadhyay et al., 2018) which took place within the context of the associated research project "Behavioral adaptations in live poultry trading and farming systems and zoonoses control in Bangladesh" (BALZAC) (Grant No. BB/L018993/1), 36 key informant stakeholders were purposively selected with the aim to capture a range of actors involved in poultry production and distribution. They were contacted through email and telephone in the last week of March 2020. Informed consent was requested prior to interviews; none of those approached refused to participate.

${ }^{1}$ Kitchen markets (kachar bazar) are markets selling a wide range of foods and goods seen as essential to daily life including fruit, vegetables and meat. 
Three groups of informants were identified. Group-1 consisted of managers or senior employees of six poultry breeder and hatchery companies, four feed companies, and four pharmaceutical companies. Group-2 included farmers from three small-scale ( $<500$ birds/farm), three medium-scale (5015,000 birds/farm), one large-scale ( $>5,000$ birds/farm) exotic broiler chicken farm, and one small-scale (1,500 birds/farm), one medium-scale (5,000 birds/farm) and one large-scale $(8,000$ birds/farm) layer farm. Group-3 included three middlemen, three feed dealers, three wholesalers and three retailers operating in markets. Although most recruited stakeholders were from Chattogram district, the companies in Group-1 were selected from across the entire country.

Participants were asked open-ended questions about the impact of COVID-19 on their business, their coping strategies, current livelihood and financial situation, assessment of the future of the poultry business in the coming months, the support they have received and their expectations of the government. The questions were adapted to the different types of stakeholders, and further probing questions were asked as appropriate. Most stakeholders were interviewed individually by cell phone, but the managers or senior employees of the breeder and hatchery companies, pharmaceutical and feed companies were emailed the questions, to which they replied by email within $2-3$ days. Faceto-face interviews were not possible during this period of research due to government sanctioned restrictions to address the spread of COVID-19. Using remote methods, however, allowed us to gather real information on stakeholder experiences in the midst of the pandemic. Oral interviews were recorded with the consent of the participants and lasted an average of $30 \mathrm{~min}$. They were conducted in Bengali by one researcher (RM) between 4 April and 2 May 2021, transcribed and translated into English. The respondents were contacted again if clarification was required.

\section{Price Monitoring}

The average daily farm gate wholesale prices of exotic broiler and Sonali chickens and eggs as reported by the Poultry Professionals Bangladesh (https://www.facebook.com/Poultry-ProfessionalsBangladesh-PPB-1597613347020175/) were recorded for 10 districts (Barisal, Bogura, Chattogram, Comilla, Cox's Bazar, Gazipur, Jashore, Mymensingh, Rajshahi, and Tangail) from January to June 2020. Nationwide price data could not be consistently recorded and the frequency of price data reporting differed between districts. Therefore, analysis of price data was limited to 10 districts where prices were most consistently reported. These cover different geographical areas of the country. Data on poultry prices prior to 2020 were not available from this source. To assess whether observed poultry price patterns could have been explained by seasonal variations, prices for the first half of 2020 were compared with poultry prices for 2016 . These data were collected through a previous study (Moyen et al., 2021). Briefly, 43 vendors operating in six markets in Dhaka and Chattogram were interviewed monthly about the price of their chickens, to assess price changes over a year. In addition, 2020's retail prices of exotic broiler and Sonali chickens and eggs in two live bird markets within Chattogram City Corporation area (Jhautola and Pahartoli urban markets) were recorded. For the period January to March 2020, these prices were supplied retrospectively by the poultry vendors operating in these markets. Prices were then monitored prospectively and daily from April to June 2020.

\section{Data Analysis}

This study was approved by the ethical committee of the Chattogram Veterinary and Animal Sciences University (Memo No: CVASU/Dir (R \& E) EC/2020/165 (10); Date: 21/07/2020).

Thematic analysis was conducted to identify and interpret the manifest and latent content of the qualitative responses following (Pope et al., 2000). For this purpose, two researchers (AAS, ASM) familiarized themselves with the transcripts of the stakeholder interviews. One of them (AAS) systematically coded the data. The coding was reviewed and iteratively amended with inputs from other researchers in the team (MAH, RM, ASM, MHU, NNC). Initial themes were then generated and discussed. They were refined and a final set of themes agreed. The temporal evolution of chicken and egg prices was visualized using Microsoft Excel 2020.

\section{RESULTS AND DISCUSSION \\ Changes in the Price of Live Chickens and Eggs Over Time \\ A distinct impact of COVID-19 on the poultry sector was a} fluctuation in live chicken and egg prices prior to, during and following lockdown (January-June 2020). For each commodity, namely exotic broiler chickens, Sonali chickens and layer eggs, wholesale farm gate prices followed similar patterns across the 10 selected districts (gray lines in Figure 1). In the following, we focus on the prices averaged over the 10 districts (black lines in Figure 1).

Prices of exotic broiler chickens, Sonali chickens and eggs decreased in the period immediately following the announcement of the General Holiday on 22 March 2020, with the greatest impact on exotic broilers. By 25 March their price had dropped by $28 \%$ compared with their price on 1 January 2020. As Ramadan started, on 24 April, the price of chickens and eggs rose(Figures 1, 2). As a result, the price of chicken also rises. This upward trend continued until the Eid-ul-Fitr, in late May. The price of exotic broiler was then almost twice as high as at the start of the lockdown. This may indicate some recovery in consumer demand brought about by activities associated with these holidays (New Age, 2020). Indeed, in Bangladesh and throughout the Muslim world, the demand for animal protein has been reported to increase during Ramadan (Poultry World, 2012). After the Eid-ul-Fitr, the price of exotic broilers saw another downturn. As the lockdown was lifted (30 May 2020), prices continued to fluctuate while remaining higher than during the pre-lockdown period. Sonali chicken prices showed smaller fluctuations. Prices increased steadily during Ramadan, and, by the end of the lockdown period, they had reached slightly higher levels than at the start of the year. Sonali chickens make up a smaller proportion of the chicken products sold as compared to broilers, and they sell for a higher price to (mostly) wealthier customers. Furthermore, while broiler chickens reach maturity in 


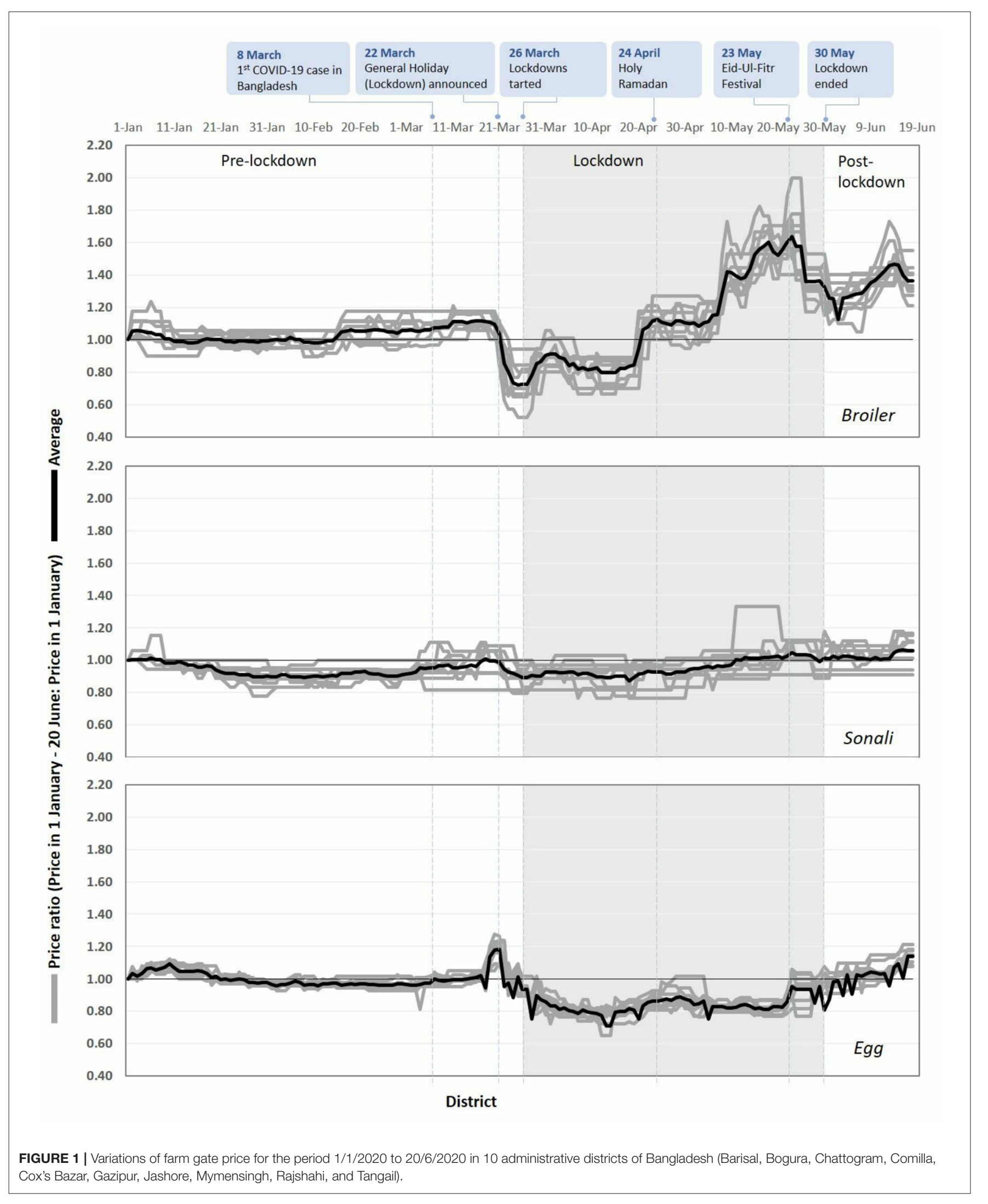




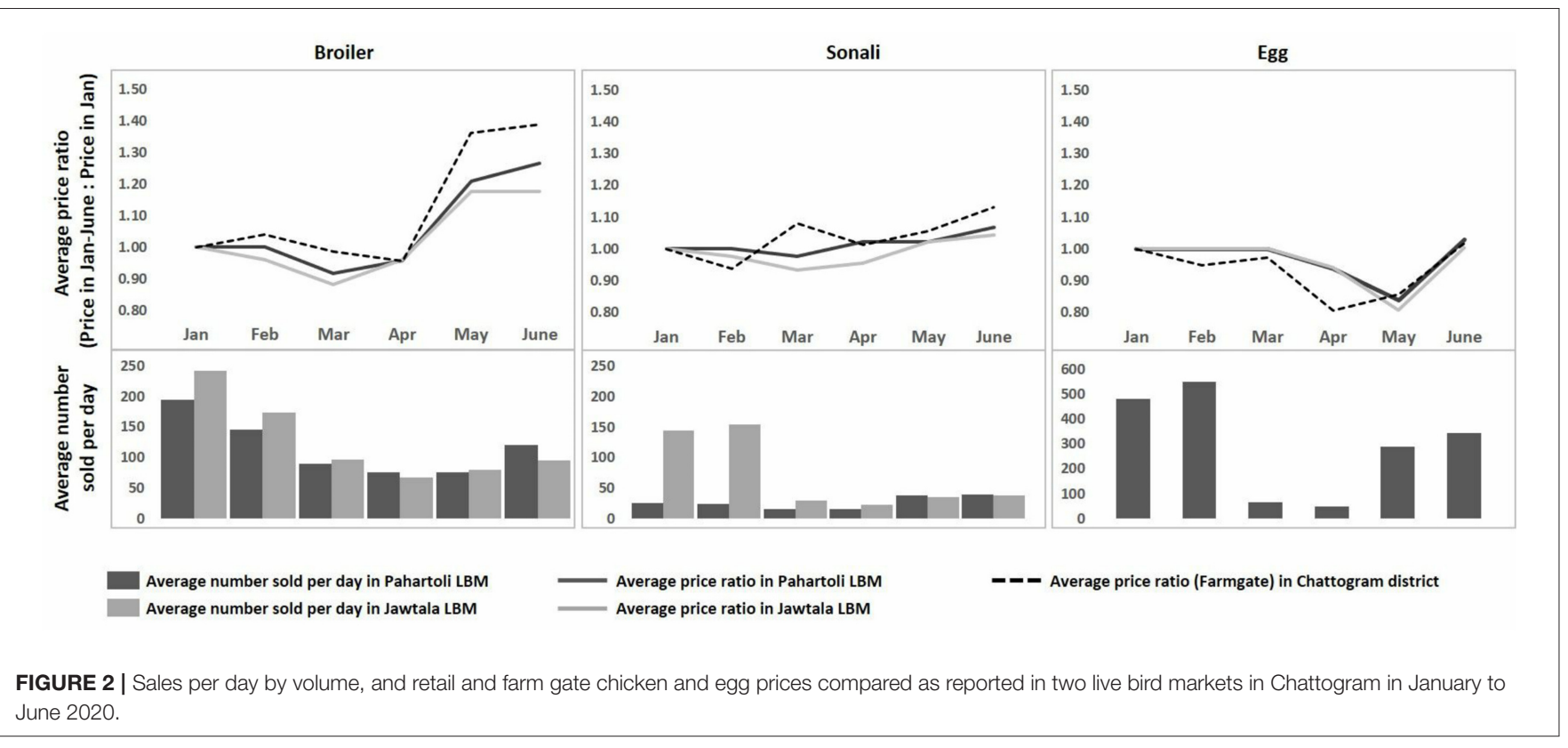

30-35 days committing producers to a relatively fast sale of flocks and hesitancy to keep them longer, Sonali chickens only reach maturity after 70-90 days so can be held back from sale for longer if the price is not satisfactory. This may be one of the reasons for Sonali chicken prices to fluctuate less than the prices of other types of chickens. Whether this is the case cannot be explored from the data reported in this study but may be answered from further research. As for eggs, prices were consistently $20 \%$ lower during lockdown than in the immediately preceding period. They attained their pre-lockdown level in the week preceding the end of the lockdown.

A comparison of chicken price ratios from January to June in 2016 (Dhaka and Chattogram markets) and 2020 (all 10 districts) suggests that this pattern is unlikely explained by seasonal variations but instead strongly influenced by the COVID-19 pandemic and associated interventions (Figure 3). While broiler chicken prices were relatively steady in the first half of 2016, they became more volatile in 2020, including an $11 \%$ drop in early April and a $40 \%$ short-term surge in late May. Monitored Sonali prices showed no major fluctuations in both years. Compared to exotic broilers the price fluctuations for Sonali were markedly less dramatic, with fluctuations during the lockdown periods no greater than during the pre-lockdown period.

We also monitored retail prices in two poultry shops in two markets of Chattogram City retrospectively (January to April) and prospectively (May and June). Similar patterns were observed in retail prices of broiler and Sonali chicken as in farm gate prices, but fluctuations of retail prices were smaller (Figure 2). For eggs, the trough in retail prices was similar, but delayed, compared to wholesale prices.

The number of exotic broiler chickens, Sonali chickens and eggs sold by our vendor informants dropped from February to March by an average of $41 \%, 74 \%$ and $88 \%$, respectively. Sales increased in May and June but remained lower than in January and February.

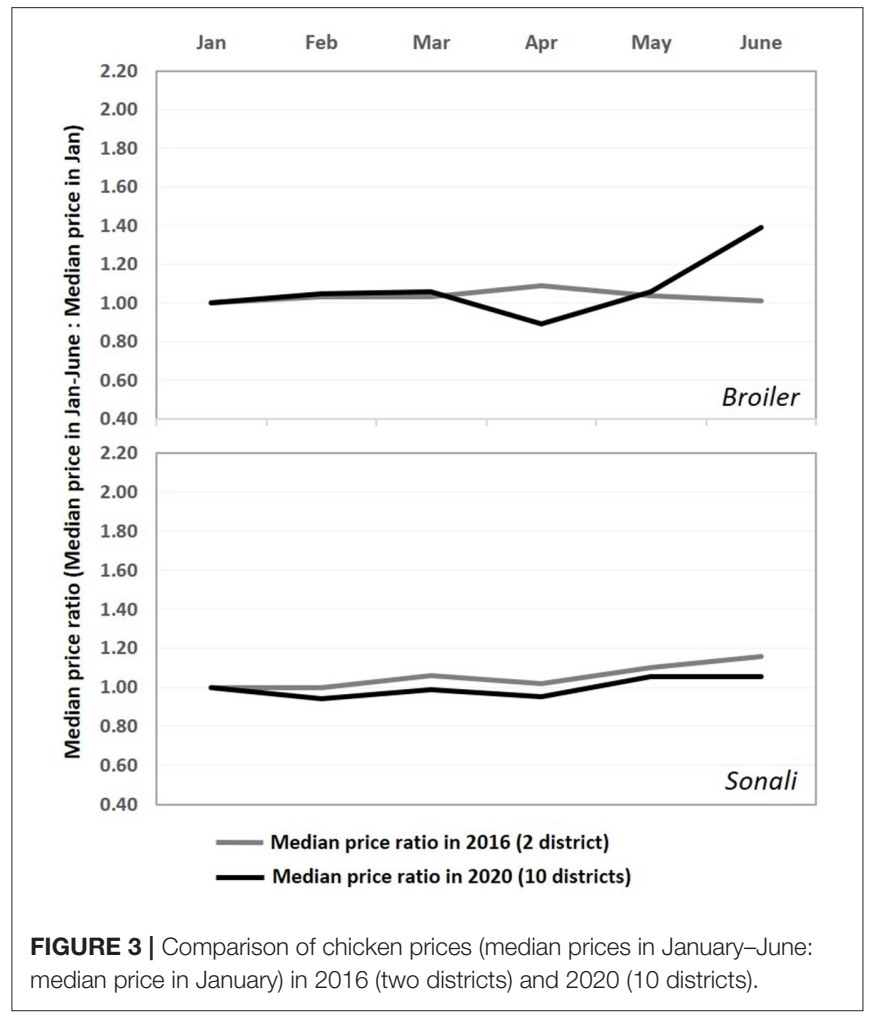

\section{Impact of COVID-19 on the Poultry Sector}

This section discusses key themes relating to the impact of COVID-19 on the poultry sector. These themes emerged from data extracted from the literature review and from interviews with stakeholders where they described the impact of the pandemic and associated lockdown, as well as their 
expectations of interventions that could help the industry in the future.

\section{Movement Restrictions and Supply Chain Disruptions}

Disruption to supply chains at a global level and local limitations on movement both had implications for Bangladesh's poultry sector. Suppliers reported that disruption in global trade meant they could not import component raw materials to produce feed and medicine. This is supported by reports of prolonged border closures preventing the import of essential feed items like maize. Production in pharmaceutical industries was also severely disrupted as the import of Active Pharmaceutical Ingredients (API) was blocked (IDLC, 2020). In addition, due to an absence of necessary equipment, regular testing of imported feed ingredients at the country's sole diagnostic laboratory was suspended (Khan, 2021). This meant that raw materials were delayed at the port, resulting in severe reductions in overall production. The shortage of laborers in the lockdown situation also slowed operations in the feed industries (Food Agriculture Organization, 2020b). Overall, feed production decreased by near $40 \%$ between April and June 2020 (Saeque, 2020).

Delays processing goods at ports of entry meant demurrage had to be paid, advanced income tax and non-withdrawal of corporate tax further increased costs for the industry (The Independent, 2020). One of the interviewees, the general manager of a multipurpose agro-based industry, expressed concern over the surplus charges for such delayed imports:

\section{"The government may take steps to reduce import tariff, VAT, and other taxes for agro-based companies as compensation for the unforeseen circumstances during the pandemic."}

In addition, as a result of the lockdown imposed in the last week of March 2020, the movement of all types of vehicles was extremely limited (World Health Organization, 2020b).

Feed dealers and middlemen, who act as important intermediaries in the poultry distribution network in Bangladesh, faced huge challenges as a result of all of the factors reported above. Although the authorities announced that the transport of food items would not be subject to delay, administrative confusion meant that law enforcement agencies frequently obstructed the movement of livestock and poultry feed vehicles (Food Agriculture Organization, 2020b).This along with drivers' fears of being affected by the virus, resulted in general shortages of transport. According to a rapid assessment report released by the FAO, only $15 \%$ of trucks were active in April and May in comparison to March, and more than $40 \%$ of drivers refrained from driving, leading to a vehicle crisis that forced stakeholders to pay extra for moving their goods (Food Agriculture Organization, 2020b). According to one feed dealer:

\section{"In the current situation, renting vehicles to transport poultry feed costs almost 1.5 times as much as usual."}

The impact of these disruptions for input suppliers also had consequences for farmers, some reporting that difficulty accessing feed and essential medicines were negatively affecting their ability to continue their farming operations. These difficulties further affected farmers when it came to trying to distribute their goods, with movement restrictions and higher transport costs disrupting their standard business practices. For example, a large portion of the country's total Deshi chickens come from the backyard poultry farmers in the north, who rely on a variety of transport links to supply different parts of the country. These routes were completely shut down due to movement restrictions. This caused financial loss to the backyard farmers and traders. A wholesaler who would usually have traded Deshi chickens from these regions, described his difficulties as follows:

"The demand for Deshi chicken has decreased by about 50\%. In my stall, most of the Deshi chicken and duck come from other districts mainly from the northern part by using rooftops of public transport. Now, the transportation fares are higher, and the supply has decreased by $80 \%$."

\section{A Drop in Demand}

In 2018-19, the total production of eggs in Bangladesh was 17.11 billion. This met $98.8 \%$ of the country's demand. Overall meat production was 7.6 million metric tons (MOFL-Ministry of Fisheries Livestock, 2020a). In 2019, poultry meat made up $37 \%$ of production (FAOSTAT, 2019). After March 2020, these production levels fell by at least half (Berkhout, 2020): disruption to supply and transport was a major reason for this. Another is that COVID-19 caused the demand for chickens and eggs to fall. Input suppliers noticed the demand for poultry and poultry products dropped dramatically with the onset of the COVID-19 crisis. The Assistant General Manager of one of the country's leading day-old chicks and poultry feed producing companies said:

"People avoided consumption of chicken and egg as the COVID-19 outbreak had started. Besides, consumers were unable to go to the markets due to the lockdown, which significantly reduced demand for meat, egg, and other processed food."

This had a significant adverse effect on all stakeholders along the transaction chain, from producers to sellers, resulting in a sharp fall in chicken prices and sales over a very short period. Informants suggested two key reasons for these changes: (i) lockdown restrictions limited both business opportunities and customer incomes, and (ii) rumors circulated which suggested that poultry products spread COVID-19. We shall consider each of these in turn.

\section{The Effect of Lockdown Restrictions on Demand}

A key part of the disruption occurred when retailers reported that they could not continue normal trading practices in markets and shops. This resulted from government restrictions on all businesses in an effort to prevent public gatherings (World Health Organization, 2020b). Exceptions were made for "emergency services" which included food stalls and kitchen markets. Even those emergency services permitted to remain open had to close by 7 p.m. (TBSNEWS, 2020). In addition, various social, religious and political events such as weddings, 
parties, religious gatherings, election campaigns, where chicken and eggs were necessary food items, were banned (Ali, 2020).

In the case of markets, some had to close or adapt their business practices. Thus, to ensure social distancing among shoppers, markets were later relocated from their permanent places to more open spaces (Mahmud, 2020) and the use of masks by workers was made mandatory. With limited business hours, new locations, and rising infection rates, the presence of customers in the poultry market during lockdown declined by over a third (Rosen, 2020). In their interview responses, traders reported that the emphasis placed on social distancing by health experts and politicians meant consumers became less willing to visit markets and other crowded places. One retail poultry vendor observed that:

"Due to the imposed restricted movements and instructions of maintaining social distance by the authorities, the number of chicken buyers, especially the middle-class consumers, in the market has decreased even though the price is very low now (in April). Moreover, many middlemen have temporarily suspended the supply of chickens to the market due to the risk of being infected."

A wholesaler who bought chickens from different parts of the country and sold them in an LBM in Chattogram commented:

\footnotetext{
"The upper and upper-middle-class people did not come to LBM at the time of the lockdown regularly like before, but basically, they are the main buyers of Deshi chickens."
}

The closure of hotels, restaurants, bakeries and other industries also contributed to the drop in demand. A middleman who used to regularly supply broiler and Sonali chickens to wholesalers, retailers, and other establishments, said:

\begin{abstract}
"Hotels, restaurants, and individual stalls which were our key customers are now closed. Besides, we also used to sell a huge number of chickens in Export Processing Zone (EPZ), to garments factories, and residential hostels of universities and colleges which are temporarily closed. In typical times where I was able to trade at least three truckloads of chickens per day, now I can sell only one truckload every other day."
\end{abstract}

Poultry traders also reported that the gradual increase in the severity of lockdown measures (World Health Organization, 2020b), including the temporary closure of businesses and workplaces, had reduced consumer incomes. They speculated that many people could no longer afford to buy chickens even if they were able to adapt to new market systems. These responses are in keeping with the findings of recent reports in which job losses or disruptions in the ability to do certain jobs during lockdown diminished many people's income (Islam and Babu, 2020; Rahman and Ruszczyk, 2020). In one report exploring COVID's impact on the labor market in Dhaka and Chittagong City Corporations, $22-25 \%$ of people reported losing their jobs either permanently or temporarily as a result of disruptions linked to COVID-19 (Genoni et al., 2020). According to one study, about $95 \%$ of households experienced income loss in the first two months of the pandemic, and $62 \%$ of earners reported lost jobs (Miah et al., 2020).

\section{The Impact of Rumors}

Unfounded reports and rumors circulated quickly and widely in the early months of the pandemic. Propelled into popular discourse via social and some mainstream media, one rumor that gained public attention was that consumption of poultry and poultry products could cause COVID-19 (Islam and Babu, 2020; Mahmud, 2020). Informants we interviewed identified these rumors as a reason for reduced chicken consumption. A farmer who had a flock of 4,500 broiler chickens and who had lost nearly BDT 0.1 million in April 2020 alone commented:

"At this time of uncertainty, people are afraid to eat chicken, a large part of the public, especially the villagers, believe that eating chicken meat is likely to cause COVID-19."

Another informant, a wholesaler and retailer of both broiler and Sonali chickens, said:

\begin{abstract}
"A large portion of regular chicken buyers are currently absent from the market; many also believe that COVID-19 may be transmitted to humans from poultry and poultry products. The declining sales volume has already caused me a huge loss."
\end{abstract}

Several news articles also presented the rumors as a major cause of the drop in consumer demand (Ali, 2020; Sharma, 2020). These describe how misconceptions about the potential transmission of COVID-19 by chickens and other meat products led consumers to cut back on chicken consumption, contributing to a sharp drop in market demand with the result that prices fell by as much as 75\% (Mahmud, 2020).

Despite the temporary positive turn in price during Ramadan and Eid, feed dealers, whose role in the transaction chain is to provide credit to farmers, claimed that demand for chicken and eggs did not match that of previous years and that this prevented the input suppliers, farmers and traders from making the profits they expected. One article reporting on sales during this period noted that limited demand may not have been the only issue. It states that due to the closure of many farms, interrupted production, and transportation problems, the supply and sales volume of chickens in the market were low and it did not return to normal until June 2020 (The Observer, 2020). Thus, although prices may have increased in response to increasing demand during this period, that does not necessarily indicate a substantial enough recovery throughout the production and distribution network for stakeholders working across the industry to bounce back and function as they had prior to COVID-19.

\section{Economic Consequences}

Disruption to business across the production and distribution network resulted in price fluctuations and financial losses for stakeholders across the sector. In an overview of the impact the pandemic had, the Bangladesh Poultry Industries Central Council (BPICC) reported an approximate loss of above BDT 300 billion in the country's poultry industry between 26 March and 30 April 2020 (Ali, 2020). 
It is normal for the prices of chickens and eggs to varying over the year and so some stakeholders anticipated market volatility as soon as the pandemic began. However, despite varying levels of anticipation, most were unable to respond rapidly. Initially, prices of chickens and eggs fell due to lower-than-normal demand, and then rose dramatically during Ramadan. The initial drop in price resulted in many stakeholders temporarily shutting down operations or focusing on alternative agricultural endeavors. The Bangladesh Poultry Industries Central Council (BPICC) reported that $50-60 \%$ of all poultry farms closed temporarily in response to COVID-19 (Ali, 2020). Although a portion of the broiler farmers restarted farming by June (IDLC, 2020), the permanence of most of these closures is still unclear, in February 2021, 30\% of broiler farms and hatcheries that closed due to the pandemic in April 2020 had remained closed to date (Financial Express, 2021).

Informants from all groups reported a drop in the price of their commodities and described this as a direct consequence of a fall in demand. For farmers, this meant from the earlier retail price of BDT 130-150 per kg of broiler, the price fell below BDT 90 in March and April. This was challenging for farmers as the production costs for broilers per kg were between BDT 90-100. All farmers reported that traders were also reluctant to buy their chickens and eggs due to this low price. A medium scale broiler farmer mentioned that:

\begin{abstract}
"Since the lockdown started, I have not been able to sell my chickens at the same price as before. Traders are not interested in buying chickens as before due to the risk of losses...Many poultry stalls are already closed in LBM. Mobile vendors and seasonal vendors (sell broiler chicken during the festival time) are not doing poultry business at this moment."
\end{abstract}

This is confirmed by a report from the Food and Agricultural Organization of the United Nations, stating that about $70 \%$ of chickens were said to remain unsold (Food Agriculture Organization, 2020b). As a result, farmers were forced to sell birds and eggs at a very low price. A large-scale broiler farmer, who for decades had reared flocks of more than 5,000 birds, shared his experience saying:

"I never experienced this kind of critical situation in the last 10 years. I cannot sell mature broiler to middlemen even at BDT 80-90 per kg, whereas my production cost is near BDT 100 per kg."

This discrepancy between production cost and wholesale price made the business unsustainable for many farmers. Consequently, around $70 \%$ of small to medium-sized broiler farms were closed by April (IDLC, 2020). Small-scale farms were hard-hit, while many large-scale farms reduced their flock size, the result of which was that chicken meat production rapidly declined from 90,000 to 25,000-27,000 tons/month (Ali, 2020).

For layer farmers, the cost of production per egg was around BDT 5.50, but the market price fell to BDT 4.00. Nevertheless, it was reported that nearly $50 \%$ of eggs remained unsold (Food Agriculture Organization, 2020b). From the onset of the pandemic until April, 32-35\% of the layer farms were completely closed (Ali, 2020). During interviews, farmers reported selling their laying hens as spent hens before the end of their laying cycle to reduce financial losses.

Both broiler and layer farmers expressed concerns about the sustainability of their activity. This was due to the price fluctuations, particularly for broilers, where the impact was amplified because farmers depend on credit provided by feed dealers. The credits are usually reimbursed at the end of the batch production cycle, the sale was often managed, and prices negotiated by the feed dealers/lenders. However, due to the adverse situation brought on by COVID-19, farmers were unable to repay their creditors. Some marginal small-scale farmers stopped poultry farming temporarily or permanently and reported setting up new agricultural activities or non-agricultural small-scale businesses instead. Describing his plight, a small-scale broiler farmer (1,500 bird) stated:

"If this situation lasts, I will have to leave poultry farming forever. I have already lost BDT 100,000 with the last batch. The feed dealer is pressuring me to reimburse my credit. I am now doing other agricultural work on my land, and I had to sell my cow as I needed cash."

If a farm closes, as described in the quote above, dealers cannot recover the arrears owed by farmers. In a word, the unanticipated incidents in the poultry sector disrupted the cash flow among all the stakeholders associated with the entire transaction chain.

Input suppliers also reported a loss of income. According to a senior official at one of the country's leading poultry hatcheries:

"Chicken prices are usually slightly higher in March and April, so this is a profitable season for poultry traders and producers. But with the onset of the pandemic in the country and the government's declaration of lockdown on March 26, the situation was completely reversed. Broiler and layer DOC prices had come down from BDT 30 and 40 to BDT 15 and 18, respectively."

The prices of day-old layer chicks and broiler chicks reportedly declined by 75 and $90 \%$, respectively. Besides, $40-50 \%$ of newly hatched DOCs were reported to be unsold (Food Agriculture Organization, 2020b). Several hatcheries reported that they had to cull unsold DOCs and sell hatchable eggs as table eggs at the very low price of BDT 3.9-5.5 (USD 0.046- 0.065). Noting the comparative difference between the DOC production cost and the selling price, the general manager of an agriculture-based company commented:

"The sale price of broiler DOC dropped below the production cost. Now, broiler DOC selling price is BDT 4-5, whereas it was around BDT 35 before COVID-19. Our production cost is around BDT 3032. So, we had to reduce the weekly production of DOCs from 13 million to 7.5-8 million."

Consequently, hatcheries, breeders and feed industries had to reduce the production of DOCs, feed and medicine in an attempt to mitigate their financial losses. Bangladesh Poultry Industries Central Council (BPICC) found near 50\% of the hatcheries ceased DOC production (Ali, 2020), and overall 
poultry production nosedived to almost $50 \%$ in a matter of months (Berkhout, 2020). A report of 120 hatcheries that used to produce 1.4 million broiler chicks and 17 million layer chicks weekly, dropped to around 9 million as many commercial poultry farmers postponed farming (Ali, 2020).

While some participants described the adverse effects of falling demand on their business and the actions they took to mitigate financial losses, traders reported additional causes for the financial losses they experienced. These included higher transportation costs, restricted business hours, the management of an unusually high number of unsold birds, and the inability to reduce their daily expenditures despite the reduction of their business. Referring to the overall loss due to regular expenses regardless of deficient income, one wholesaler commented:

\begin{abstract}
"Revenues have reduced with declined price and supply. But you know, my operational cost did not decrease, I have to pay the rent of the shop, the salary of the staff, utility bill, etc. In the last three months, I have lost around BDT 400,000-450,000 from my capital."
\end{abstract}

Wholesalers and retailers also reported that due to low consumer demand and restricted business hours (10 a.m. to 4 p.m.), many more birds than usual were left unsold every day meaning that vendors had to bear the cost of keeping them alive (Figure 4).

\section{Appeals for Intervention and Support}

Despite government efforts to limit financial loss across the sector in the form of cash incentives (Amin, 2020; MOFL-Ministry of Fisheries Livestock, 2020b), subsidized feed, medicines and vaccines (AgriNews24, 2020), and health messaging to counteract rumors (UNB, 2020), informants from all stakeholder groups still described the need for financial support from the government and urged national and international NGOs and multilateral organizations to help. Notably, poultry traders did not expect to receive any financial support from the government themselves but supported the government for small-scale, marginal farmers.

Most respondents in the input suppliers group reported that they had already sought interest-free or low-interest loans from the government together with the cancellation of utility bills. For farmers, however, concerns were raised about access to the stimulation package offered by the government. Only one small-scale broiler farmer whom we interviewed reported having benefited from governmental and NGO financial support. Another, who had reduced his flock size by about two-thirds expressed fears that:

"I haven't got any government support yet. I am sure if the government provides financial support, it won't reach us at all. It will be for big poultry farms or companies."

Respondents from all groups also recommended that the government should intervene to stabilize prices. Some specifically sought government intervention as some trading syndicates were reportedly seeking to control the poultry market by manipulating prices. Both farmers and traders highlighted the volatility of production input and output prices as an issue, with farmers' concerns focusing particularly on DOC, eggs and mature birds, and their consequences for the future of their activity.

Informants from the input suppliers group urged the government to reduce import taxes on agricultural products. They also asked that government raise public awareness to curb misinformation connecting chickens to the spread of COVID-19.

\section{CONCLUSION AND RECOMMENDATIONS}

Ultimately, this work has shown that the lockdown that was put in place in response to the COVID-19 pandemic has had a significant effect on the poultry sector in Bangladesh. Rumors that arose during the initial lockdown period linking the disease to chicken consumption had a small, but not inconsequential impact and one that reveals the importance of accurate health messaging in times of crisis.

Crucially, although many of the disruptions identified in this study can be linked to the impact that COVID-19 has had on the poultry industry, it is important to recognize that many of the most significant consequences of the pandemic-such as the volatility of input and production prices and creditdependence-are structural factors. Rather than being created by the crisis, COVID-19 rather brought these endemic issues to the fore and previously hidden structural fragility to light (Hennessey et al., 2021). For example, price fluctuations and credit dependence were both existing concerns for farmers prior to the pandemic but became significantly damaging during the lockdown period in ways that individuals were unable to mitigate-leading to the loss of income and entire businesses closing in some cases. Therefore, while this work highlights the need for specific interventions to be implemented when facing a pandemic, it also acts as a reminder that some structural factors need to be examined in the long term, as, independently from the pandemic, they negatively impact food security, income generation for stakeholders and may well-generate other types of pandemic risk.

Based on these preliminary findings, this research indicates that the sector needs a program of effective short, medium and long-term interventions that can be implemented in response to disruptions that arise at different points of the poultry industry's extensive network. Further research would be required to understand the full extent of the impact that COVID-19 has on the sector in the longer term which is being undertaken by our research team. This study is able to suggest that any future research and development of interventions should consider the following:

- The government must be prepared to promptly disseminate public health information and develop a strategy to prevent and counter the spread of false news and misleading information in anticipation of any future pandemics. In the case of COVID-19, public information campaigns should continue to promote the dietary value of consuming eggs and chicken for overall health and immunity and provide additional resources to help consumers access poultry products safely and counter prominent rumors. 


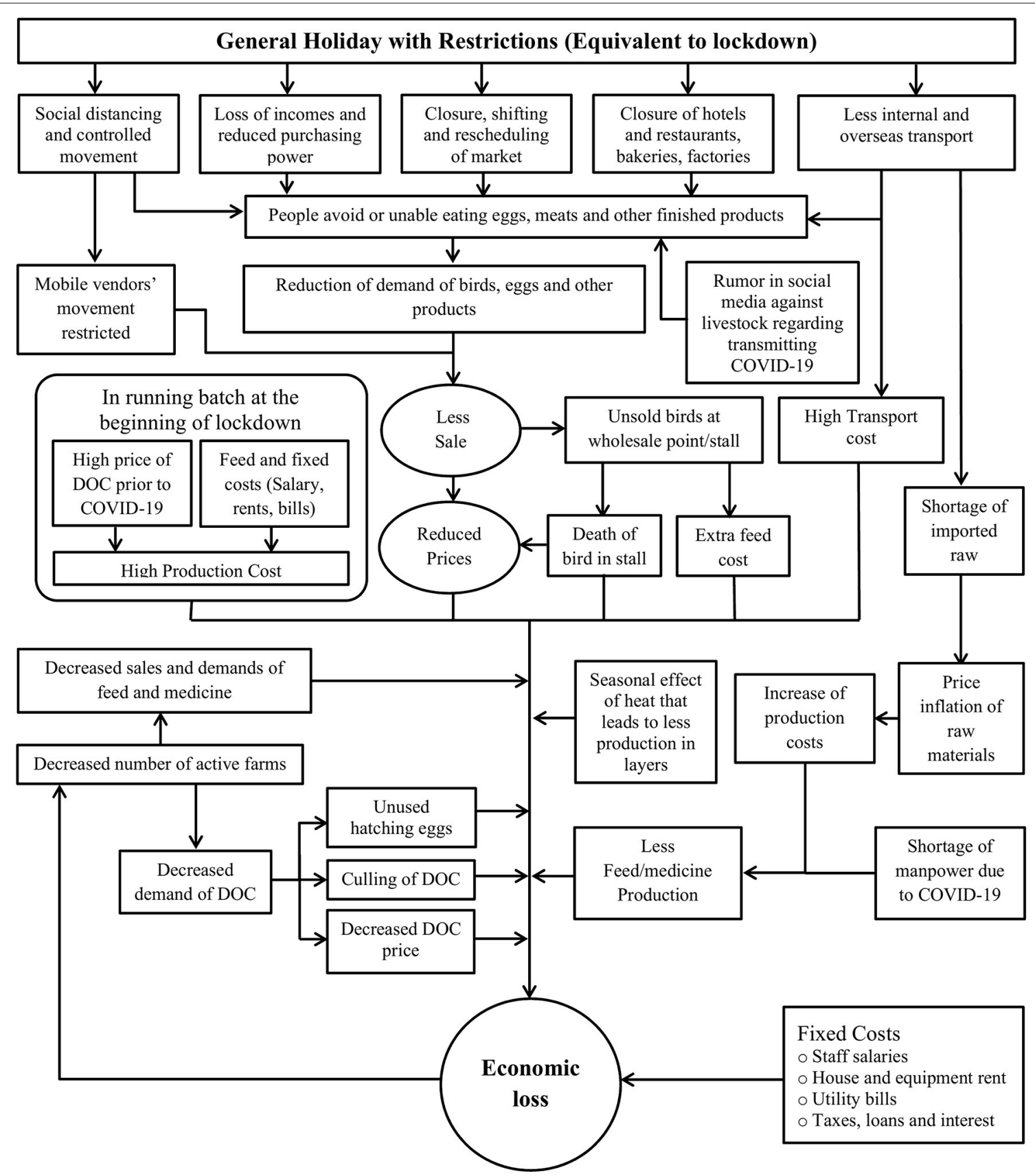

FIGURE 4 | Impact of COVID-19 on PDN in Bangladesh.

- The financial incentives announced by the government must reach vulnerable stakeholders, including marginal farmers. This will depend on better dissemination of information about what is available and consideration of how they will be accessed. Specifically, the procedures of getting and repaying bank loans need to be made more flexible for the agricultural and livestock sector, with government acknowledgment of the complex financial relationships businesses may be reliant on.
- The COVID-19 pandemic has highlighted limitations to continuing safe farming and distribution practices in times of national crisis. The livestock and agriculture sector should be declared as essential or strategic activities of public interest in order to continue smooth production during the COVID19 pandemic. It is also essential to develop a medically responsible, unobstructed and fast transportation system to maintain the proper distribution of agricultural products around the country during any crisis. 
- Gaining a better understanding of the underlying structural fragility of agricultural, fisheries and livestock sectors should be a priority. Doing so will enable the policy makers to develop a constructive and proactive pre-plan for rapid rehabilitation and provision of alternative income-generating activities for stakeholders involved in these sectors affected by a pandemic or other natural disasters in future.

- To connect producers, businesses and consumers in any circumstances, explore alternative sales and distribution platforms of poultry and poultry products through online resources and e-commerce to a greater degree.

- In order to ensure food security for every citizen of the country during and after the pandemic, the government must be prepared with the resources necessary to ensure optimal livestock and agricultural production, as well as equitable distribution and price regulation.

In addition to these recommendations, this research has revealed some areas warranting further investigation. Specifically, it is worth considering what the "fragility" discussed here means for how different stakeholders structure their business and strive to adapt to challenges as they arise. For those farmers suspending or closing poultry production in response to the pandemic, it may be that they were not solely dependent on this income source and were able to shift their attention to other income-generating activities. Evidence that marginal and small-scale production is more likely to have ceased operations than larger farms, should encourage us to consider whether COVID-19 marks a permanent shift in favor of larger-scale integrated production and what this would mean for the future of the poultry sector as a whole. Ultimately, although not to underestimate the challenges and losses affecting the many people who were hit hard as a result of COVID-19, we should problematize the evidence of

\section{REFERENCES}

AgriNews24 (2020). The Ministry of Fisheries and Livestock Will Provide Feed to the Farmers at Subsidized Price (In Bengali). Available online at: https://tinyurl. com/y9wz73yz (accessed December 28, 2020).

Ali, S. (2020). Poultry Production Falls Alarmingly. Available online at: https:// tbsnews.net/coronavirus-chronicle/covid-19-bangladesh/poultry-productionfalls-alarmingly- 80857 (accessed December 28, 2020).

Amin, M. A. (2020). Tackling Coronavirus: PM Announces Tk5,000cr Package for Bangladesh's Agriculture Sector. Available online at: https:// www.dhakatribune.com/bangladesh/2020/04/12/coronavirus-pm-holdsvideoconference-with-district-officials-of-khulna-barisal (accessed April 12, 2020).

Barrett, R. (2020). Wisconsin Farmers Forced to Dump Milk as Coronavirus Slams a Fragile Dairy Economy. Available online at: https://www.jsonline.com/story/ money/2020/04/01/coronavirus-forces-dairy-farmers-dump-milk-wisconsincovid-19/5108609002/ (accessed December 18, 2020).

Berkhout, N. (2020). Bangladesh Poultry Production Plummets. Available online at: https://www.poultryworld.net/Meat/Articles/2020/5/Bangladesh-poultryproduction-plummets-585903E/ (accessed December 28, 2020).

Chattopadhyay, K., Fournié, G., Abul Kalam, M., Biswas, P. K., Hoque, A., Debnath, N. C., et al. (2018). A qualitative stakeholder analysis of avian influenza policy in Bangladesh. Ecohealth 15, 63-71. doi: $10.1007 /$ s10393-017-1285-2

DLS: Department of Livestock Services (2020). Livestock Economy at a Glance. Available online at: http://dls.portal.gov.bd/sites/default/files/files/dls.portal. "fragility" seen here and consider if the survival of the sector despite this actually presents us with as yet unresearched evidence of resilience.

\section{DATA AVAILABILITY STATEMENT}

The raw data supporting the conclusions of this article will be made available by the authors, without undue reservation.

\section{AUTHOR CONTRIBUTIONS}

RM: stakeholder interview. MM, NC, MU, AS, and NI: literature review and market data collection. AS: data analysis and interpretation of results. AS and $\mathrm{EH}$ : draft manuscript preparation. TB, GF, and $\mathrm{MH}$ : critical review and feedback. $\mathrm{MH}$ : study conception and design. All authors contributed to the article and approved the submitted version.

\section{FUNDING}

This project is funded by a grant from the UK Research and Innovation Global Challenges Research Fund One Health Poultry Hub (BB/S011269/1), one of 12 interdisciplinary research hubs funded under the UK government's Global Challenges Research Fund Interdisciplinary Research Hub initiative.

\section{ACKNOWLEDGMENTS}

We would like to thank the stakeholders who participated in the study. We also thank Natalie Moyen for sharing the 2016 price data. gov.bd/page/ee5f4621_fa3a_40ac_8bd9_898fb8ee4700/2020-07-22-19-34e4cd5ed65f45419ee038e00b8939cla0.pdf (accessed December 24, 2020).

FAOSTAT (2019). Available online at: http://www.fao.org/faostat/en/ (accessed December 28, 2020).

Financial Express (2021). Poultry Meat Gets Dearer in Dhaka. Available online at: https://www.thefinancialexpress.com.bd/trade/poultry-meat-getsdearer-in-dhaka- 1614316181 (accessed February 23, 2021).

Food and Agriculture Organization (2020a). Mitigating the Impacts of COVID19 on the Livestock Sector. Available online at: http://www.fao.org/3/ca8799en/ CA8799EN.pdf (accessed December 23, 2020).

Food and Agriculture Organization (2020b). Rapid Assessment of Food and Nutrition Security in the Context of COVID-19 in Bangladesh. Available online at: https://fscluster.org/sites/default/files/documents/fao_bangladesh_covid19_rapid_assessment_report_09-05-2020_final13may2020.pdf (accessed December 28, 2020).

Genoni, M. E., Khan, A. I., Krishnan, N., Palaniswamy, N., and Raza, W. (2020). Losing Livelihoods: The Labor Market Impacts of COVID-19 in Bangladesh. Washington, DC: World Bank. doi: 10.1596/34449

Good, K. (2020). As COVID-19 Slows Meat Processing, Meat Shortages a Growing Concern; Livestock Producers Face Tough Choices. Available online at: https:// farmpolicynews.illinois.edu/2020/04/as-covid-19-slows-meat-processinglivestock-producers-may-face-tough-choices/ (accessed December 16, 2020).

Gupta, S. D., Hoque, M. A., Fournié, G., and Henning, J. (2021). Patterns of Avian Influenza A (H5) and A (H9) virus infection in backyard, commercial broiler and layer chicken farms in Bangladesh. Transbound Emerg. Dis. 68, 137-151. doi: $10.1111 /$ tbed.13657 
Hamid, M., Rahman, M., Ahmed, S., and Hossain, K. J. A. J. o. P. S. (2017). Status of poultry industry in Bangladesh and the role of private sector for its development. Asian J. Poult. Sci. 11, 1-13. doi: 10.3923/ajpsaj.2017.1.13

Hennessey, M., Fourni,é, G., Hoque, M. A., Biswas, P. K., Alarcon, P., Ebata, A., et al. (2021). Intensification of fragility: poultry production and distribution in Bangladesh and its implications for disease risk. Prev. Vet. Med. 191:105367. doi: 10.1016/j.prevetmed.2021.105367

Høg, E., Fournié, G., Hoque, M. A., Mahmud, R., Pfeiffer, D. U., and Barnett, T. (2019). Competing biosecurity and risk rationalities in the Chittagong poultry commodity chain, Bangladesh. BioSocieties 14, 368-392. doi: 10.1057/s41292-018-0131-2

Hossain, T. M. (2020). Bangladesh: Grain and Feed Annual. USDA. Available online at: https://apps.fas.usda.gov/newgainapi/api/Report/ DownloadReportByFileName?fileName=Grain\%20and\%20Feed\%20Annual_ Dhaka_Bangladesh_03-27-2020 (accessed December 22, 2020).

Huffstutter, P. J. (2020). U.S. Dairy Farmers Dump Milk as Pandemic Upends Food Markets. Available online at: https://www.weforum.org/agenda/2020/04/dairymilk-pandemic-supply-chains-coronavirus-covid19-pandemic/ (accessed December 17, 2020).

IDLC (2020). "Feed industry of Bangladesh: sustaining COVID-19 and potentials in upcoming days," in IDLC Monthly Business Review. Available online at: https://idlc.com/mbr/images/public/xWV4Ylp7Dg1TyTKLENXGmW.pdf (accessed December, 2020).

InEuropa (2020). FoodTalks: Coronavirus and Food Waste. Available online at: https://www.progettareineuropa.com/en/2020/03/foodtalks-coronavirus-andfood-waste/ (accessed December, 2020).

Islam, J., and Babu, M. U. (2020). Bangladesh Rural Economy Reels From Shutdown. Available: https://www.tbsnews.net/economy/rural-economyreels-shutdown-63994 (accessed December 28, 2020).

Khan, M. R. (2021). Lockdown Deals Fresh Blow to Poultry Farmers. Available online at: https://www.thedailystar.net/business/economy/news/lockdowndeals-fresh-blow-poultry-farmers- 2079333 (accessed April 24, 2021).

Mahmud, N. (2020). Coronavirus: Local Poultry Industry Facing a Massive Loss. Available online at: https://www.dhakatribune.com/health/coronavirus/2020/ 04/03/coronavirus-local-poultry-industry-facing-a-massive-loss (accessed December 28, 2020).

Marchant-Forde, J. N., and Boyle, L. A. (2020). COVID-19 effects on livestock production: a one welfare issue. Front. Vet. Sci. 7:585787. doi: $10.3389 /$ fvets.2020.585787

Miah, A. S. M. J., Islam, T., Anika, I. A., and Swarna, N. R. (2020). Economic Impact of COVID-19 and Way forward for Bangladesh. Available online at: https://www.brac.net/images/news/downloads/Economic-Impact_ PPT_9\%20June_final.pdf (accessed December 28, 2020).

MOFL-Ministry of Fisheries And Livestock (2020a). Demand and Supply of Livestock in Last 10 Years. Available online at: shorturl.at/hqwS2 (accessed January 1, 2021).

MOFL-Ministry of Fisheries And Livestock (2020b). Due to the Outbreak of Nobel Coronavirus, the Formulation, and Management of Refinancing Schemes Worth BDT 5,000 Crore for the Provision of Working Capital in the Agricultural Sector (In Bengali). Available online at: https://mofl.gov.bd/sites/default/ files/files/mofl.portal.gov.bd/divisional_noc/9646112a_e6ab_47cd_8361_ 03885933294d/Bangladesh\%20bank.pdf (accessed November, 2020).

MoFood-Ministry of Food (2020). Bangladesh Second Country Investment Plan Nutrition-Sensitive Food Systems (CIP2 2016-2020) Monitoring Report. Available online at: https://mofood.portal.gov.bd/sites/default/files/files/ mofood.portal.gov.bd/policies/9671c0af_d252_4042_8d86_b09ca74cc258/ MonitoringReport2020.pdf (accessed December 28, 2020).

Moyen, N., Hoque, M. A., Mahmud, R., Hasan, M., Sarkar, S., Biswas, P. K., et al. (2021). Avian influenza transmission risk along live poultry trading networks, Bangladesh. Nat. Sci. Rep. (Under review).

Mulder, N. (2020). Poultry Quarterly Q3 2020, Fragile Recovery After Covid-19 Storm. Available online at: https://avicultura.info/en/poultry-quarterly-2020fragile-recovery-after-covid19-storm/ (accessed December 18, 2020).
New Age (2020). Prices of Ramadan Essentials Rise. Available online at: https://www.newagebd.net/article/105050/prices- of-ramadan-essentialsrise.\%20Accessed:\%20September\%202020 (accessed December 24, 2020).

Pope, C., Ziebland, S., and Mays, N. (2000). Qualitative research in health care. Analysing qualitative data. BMJ 320, 114-116. doi: 10.1136/bmj.320.722 7.114

Poultry World (2012). Bangladesh Allows Egg Imports to Meet Ramadan Demand. Available online at: https://www.poultryworld.net/Broilers/Markets- Trade/2012/6/Bangladesh-allows-egg-imports-to-meet-Ramadan-demandWP010484W/ (accessed December 24, 2020).

Rahman, M. F., and Ruszczyk, H. A. (2020). Coronavirus: How Lockdown Exposed Food Insecurity in a Small Bangladeshi City. Available online at: https:// theconversation.com/coronavirus-how-lockdown-exposed-food-insecurityin-a-small-bangladeshi-city- 140684 (accessed December 28, 2020).

Rosen, L. (2020). Field Notes: Bangladesh in Times of COVID-19 and Food Security Implications. Available online at: https://fish.cgiar.org/news-and-updates/ news/field-notes-bangladesh-times-covid-19-and-food-security-implications (accessed December 28, 2020).

Saeque, M. A. (2020). Mitigating the Impact of COVID-19 on Poultry Sector. Available online at: https://www.aci-bd.com/all-news/mitigating-the-impactof-covid-19-on-poultry-sector.html (accessed December 26, 2020).

Sharma, S. (2020). Poultry Sector Loses Hope as Sales Hit More by Rumours Than Lockdown; Govt Says, Eating Chicken Safe. Available online at: https://www. financialexpress.com/economy/poultry-sector-looses-hope-as-sales-hitmore-by-rumours-than-lockdown-govt-says-eating-chicken-safe/1917922/ (accessed December 28 2020).

TBSNEWS (2020). Close Shops, Supershops, Kitchen Markets by 7pm Daily: DMP. Available online at: https://www.tbsnews.net/coronavirus-chronicle/covid-19bangladesh/close-shops-supershops-kitchen-markets-6pm-daily-dmp-65857 (accessed December 28, 2020).

The Independent (2020). Poultry Industry Hit Hard. Available online at: https:// www.theindependentbd.com/post/243190 (accessed November 28, 2020).

UNB (2020). Crisis in poultry, Dairy Sector: Ministry to Open Control Room. Available online at: https://unb.com.bd/category/Bangladesh/crisis-inpoultry-dairy-sector-ministry-to-open-control-room/48543 (accessed November 27, 2020).

World Health Organization (2020a). Bangladesh COVID-19 Situation Report No. 10. Available online at: https://www.who.int/docs/default-source/searo/ bangladesh/covid-19-who-bangladesh-situation-reports/who-ban-covid-19sitrep-10.pdf?sfvrsn=c0aac0b8_4 (accessed December 20, 2020).

World Health Organization (2020b). Bangladesh COVID-19 Situation Report No. 4. Available online at: https://cdn.who.int/media/docs/default-source/searo/ bangladesh/covid-19- who-bangladesh-situation-reports/who-ban-covid-19sitrep-04.pdf?sfvrsn=69b6d931_8 (accessed December 23, 2020).

Conflict of Interest: The authors declare that the research was conducted in the absence of any commercial or financial relationships that could be construed as a potential conflict of interest.

Publisher's Note: All claims expressed in this article are solely those of the authors and do not necessarily represent those of their affiliated organizations, or those of the publisher, the editors and the reviewers. Any product that may be evaluated in this article, or claim that may be made by its manufacturer, is not guaranteed or endorsed by the publisher.

Copyright (c) 2021 Sattar, Mahmud, Mohsin, Chisty, Uddin, Irin, Barnett, Fournie, Houghton and Hoque. This is an open-access article distributed under the terms of the Creative Commons Attribution License (CC BY). The use, distribution or reproduction in other forums is permitted, provided the original author(s) and the copyright owner(s) are credited and that the original publication in this journal is cited, in accordance with accepted academic practice. No use, distribution or reproduction is permitted which does not comply with these terms. 